\title{
Wilhelm Rühl-Dillenburg
}

Unser langjähriger treuer Mitarbeiter, Wilhelm Rühl, ist im 63. Lebensjahre seinem längeren Leiden erlegen.

Er hat sich vom Feldmesser zum fleißigen Studenten und dann 12 Semester hindurch zum praktischen Arzt durchgearbeitet. Sein über-raschend scharfes Orientierungsvermögen hat ihn als Schüler KaÜenbachs in der Praxis durch eigenes Streben zu einer hervorragenden operativen Technik gelangen lassen. Er machte sich zunächst durch seine sehr erfolg-reichen vaginalen Uterusfixationen bemerkbar. Dann aber hat er sich eifrig der Geburtshülfe hingegeben, und zuletzt zu einemhervorragenden abdominalen Chirurgen entwickelt. Nur sehr selten fand er Zeit zu literarischer Betätigung. Seiner letzten Mitteilung, die er der Monatsschrift anvertraute (Bd. XXIX. Heft 3), werden sich unsere Leser noch gern erinnern. Unter den gynäkologischen Praktikern wird Rühls Name allzeit an hervorragender Stelle aufgenommen werden. Wir bewahren dem überaus bescheidenen und liebenswürdigen Kollegen ein treuehrendes Andenken. A. M. $\mathrm{Zu}$ dem NaehГuf für Köberlé.

Wir hatten die Notiz über die für den Verstorbenen errichtete Büste dem Werk von Pichevin entnommen. In sehr dankenswerter Weise teilt mir Herr Fe.hling mit, daß es überhaupt nicht zu der Herstellung einer solchen Büste gekommen ist. Unter den antideutschen Freunden Köberlés war für eine solche Büste gesammelt worden, welche in dem Spitalgarten aufgestellt werden sollte. Bei Ausbruch des Krieges ist derjenige, welcher diese Sammlung leitete, aus dem Elsaß verschwunden. Was aus der Sammlung geworden ist, ist unbekannt. -4- M.

Personalien.

In Basel hat sich Dr. Paul Hussy als Privatdozent für Geburtshülfe habilitiert. Seine Habilitationsschrift, ,Virulenzbestimmung und V1/8ulenz-bekämpfung" wird demnächst in der Monatsschrift erscheinen. Seine Probe-vorlesung lautet ,,Wehenschwäche und Wehenmittel”. 